\title{
The Impact of Mobile e-Commerce on GDP: A Comparative Analysis between Romania and Germany and how Covid-19 Influences the e- Commerce Activity Worldwide
}

\author{
Florin-Valeriu PANTELIMON, Tiberiu-Marian GEORGESCU, \\ Bogdan-Ştefan POSEDARU \\ Bucharest University of Economic Studies, Romania \\ pantelimonflorin15@stud.ase.ro, tiberiugeorgescu@ase.ro,posedarubogdan10@stud.ase.ro
}

\begin{abstract}
During recent years, there has been an increase in the usage of mobile devices as well as a widening of the range of activities that can be performed using them. Thus, a new field of study has been developed, the mobile commerce, which represents the activity of using mobile devices (phones, tablets or any other portable devices) to buy and sell products and services through online store platforms, whether they are business to business, business to customer or customer to customer. Our study consists of two parts, the first one analyses the impact of the mobile commerce's growth on the Gross Domestic Product for both a West European country Germany and an East European country - Romania from 2014 to 2019. The analysis aims to understand the mobile commerce importance in the pre-COVID-19 era, in the context of stable economies. The second part studies the general consumer behavior towards classic commerce and electronic commerce in the context of COVID-19 pandemic state. In this regard we analyzed data for January-April 2020 and studied the main changes for the countries which were either early affected by the pandemic, severely affected or both.
\end{abstract}

Keywords: e-Commerce, Mobile commerce, Comparative analysis, Covid-19

DOI: $10.24818 /$ issn14531305/24.2.2020.03

1 Introduction

Electronic commerce, abbreviated as ecommerce, represents the economic activity of buying and selling products and services through online platforms. E-commerce includes a wide range of economic activities such as retail stores, online banking services, transport and hotel booking services, money transfer, online payments, digital content, etc. All these activities can occur in all the three main transaction categories: business to business, business to customer and customer to customer.

Mobile commerce, or m-commerce, represents all the activities mentioned above that are performed using a portable device such as a phone, a tablet or even newer devices such as smart wearables. The increase of the use of mobile devices in order to perform economic activities in online environments has led to the development of a whole new field of study designed to ease the process of completing a specific order. Therefore, most of the platforms that offer electronic commerce services have either mobile optimized versions or native applications that shorten the number of steps required to place an order, from adding products to the cart to completing the payment.

Furthermore, there are some adjacent fields that have developed as a consequence of the rise of electronic commerce such as storage and transportation services, supply chain management, electronic marketing, software development, user interface and user experience development. Some of these fields have been influenced by the mobile commerce as well. Nowadays, native mobile applications and progressive web applications have an important role in the mobile commerce scene, as they are optimized to require the lowest number of steps possible since landing on the home page to completing an order. Various papers discuss the importance of the user experience in the electronic markets nowadays, such as [1], [2].

As the digital markets are increasing, the focus on user experience increases as well. User interface developers become more and 
more specialized, being trained and responsible for designing user-friendly interfaces that leave no room for mistakes. Electronic marketing is shifting more and more towards mobile marketing, which is responsible for tracking the users' activity, identifying their behavioural patterns and trying to promote the best advertisements, products and services in order to maximize the probability that they will buy a product or service.

Moreover, as technology advances and so does the need to focus more on the user experience, some new concepts start to gain traction and develop alongside mobile commerce. One of them is Augmented Reality (AR), which represents the simulation of a real-world experience by overlapping multiple sensorial computer-generated information (visual, auditory, haptic) with existing environments. Figure 1 illustrates the evolution of the number of virtual reality and AR users in the United States of America from 2018 to 2020 and also predicts the evolution for the next years.

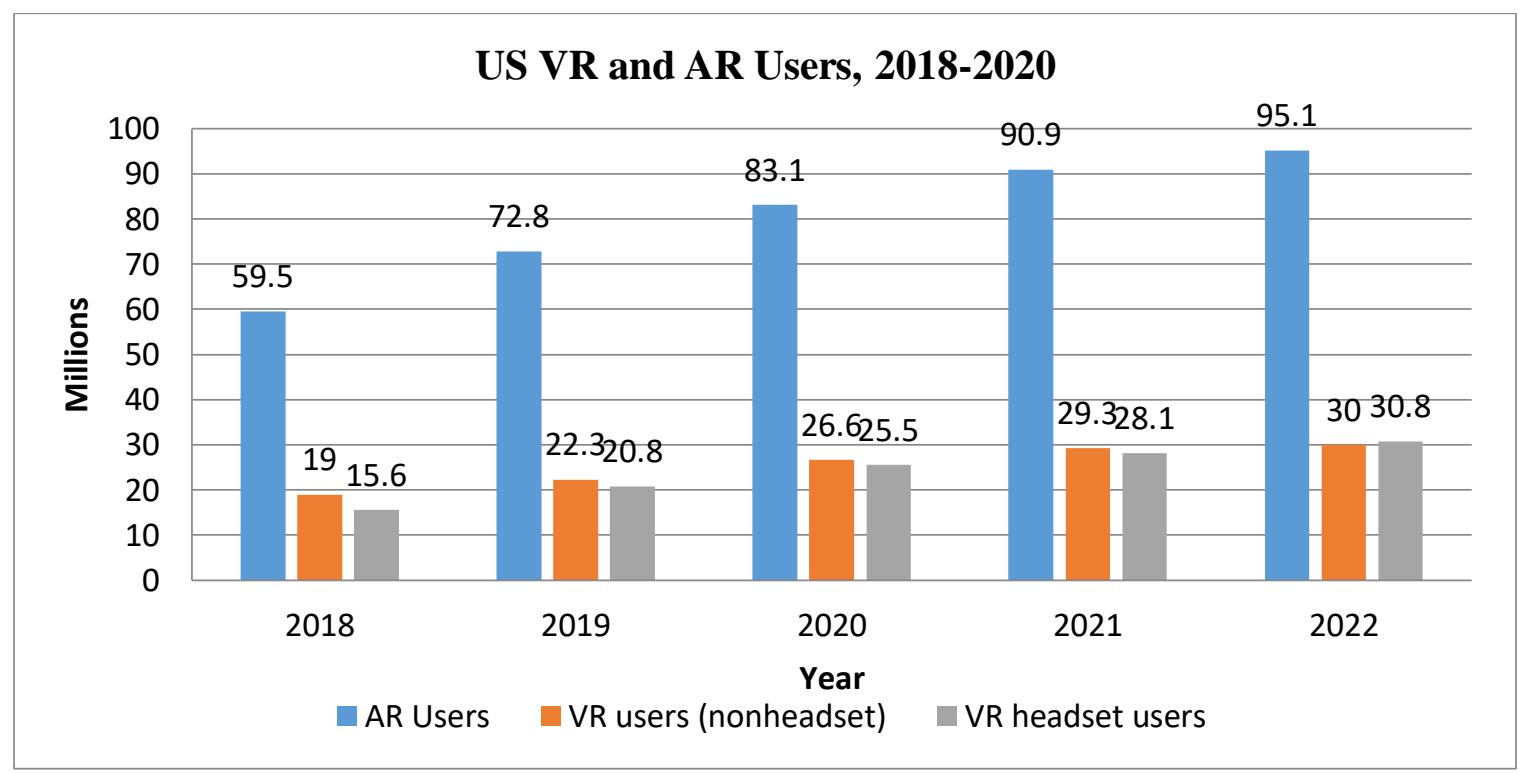

Fig. 1. Statistics regarding the AR and VR users in the United States of America Source: [3]

Article [4] discuss user interface and user experience of VR in e-commerce. Private companies are adapting to the new technologies. As an example one of the most important furniture companies in the industry launched an Augmented Reality application through which users can try different products using their smartphones' cameras [5]. This application allows customers to improve the decision-making process when buying a new piece of furniture.

AR technologies are implemented by other industries as well. One of the biggest retailers in the beauty industry created the "Virtual Artist" application which allows its users to try different makeup products before actually buying them. By this, the company developed a real in-store experience that only requires a mobile phone [6].

Besides Augmented Reality, the mobile commerce industry has stimulated the development of Chatbots, software that can simulate a conversation between a customer and a customer support representative. Thus the customer support process is more efficient, as you can simply identify recurring issues and set generic to specific answers every time a user asks a question.

\section{Related work}

\subsection{Electronic commerce}

The usage of e-commerce is constantly growing as most traditional businesses started to broaden their range of target customers by going online. During the past years, e- 
commerce has been studied based on various points of view, from the most technical ones, such as security [7], [8], databases and software related issues [9] to the least technical ones, such as marketing [10], business development and other customer related issues [11].

As in any modernization of an industry, there are both advantages and disadvantages. Some of the advantages are related to the easiness the customer feels when purchasing online. Basically, people are granted access to any store around the world, with a broad variety of products to choose from, without needing to wait in a queue, with the opportunity to compare prices and make an informed choice that will provide the most satisfaction, without being limited to a certain schedule, as websites are open 24/7. Since electronic commerce raised the competition between stores, there will always be various promotions, coupons, flash discounts and other marketing techniques to place a store one step ahead of a competitor. Moreover, not only the customer has to benefit from the rise of e-commerce, but also the stores.

One of the most important advantages of operating an e-commerce platform is that there is no need for a physical store, hence no costs related to maintaining one. Also, an online store has a high scalability that comes from not being tied up to a limited space, reduced employees costs as most of the processes are automated and less people are required to take a product off the shelf and deliver it to the final customer [12].

On the other hand, there are also some disadvantages related to the usage or to the operating process of an online store. The inability to try a product before placing an order leads in some cases to unsatisfied customers, which translates into new costs for deliveries as well as another few days the customers have to wait before getting the new product. This represents a disadvantage for both parties involved as in many cases, the store operator has to support the costs of this entire process.

Another important disadvantage is represented by the security issues. Identity theft and credit card fraud are the main threats both consumer and business face when making online transactions. However, both of them have been placed under strict regulations, as most countries implemented data privacy laws and also there were set certain security standards for online payments, such as 3D secure in the European Union [12].

\subsection{Mobile commerce}

The usage of smartphones has raised to the point that as of January 2020 there were almost 4.54 billion of internet users around the world, which translates into a total of $59 \%$ of the population and 4.18 billion of unique mobile internet users, as can be observed in figure 2 [13]. 


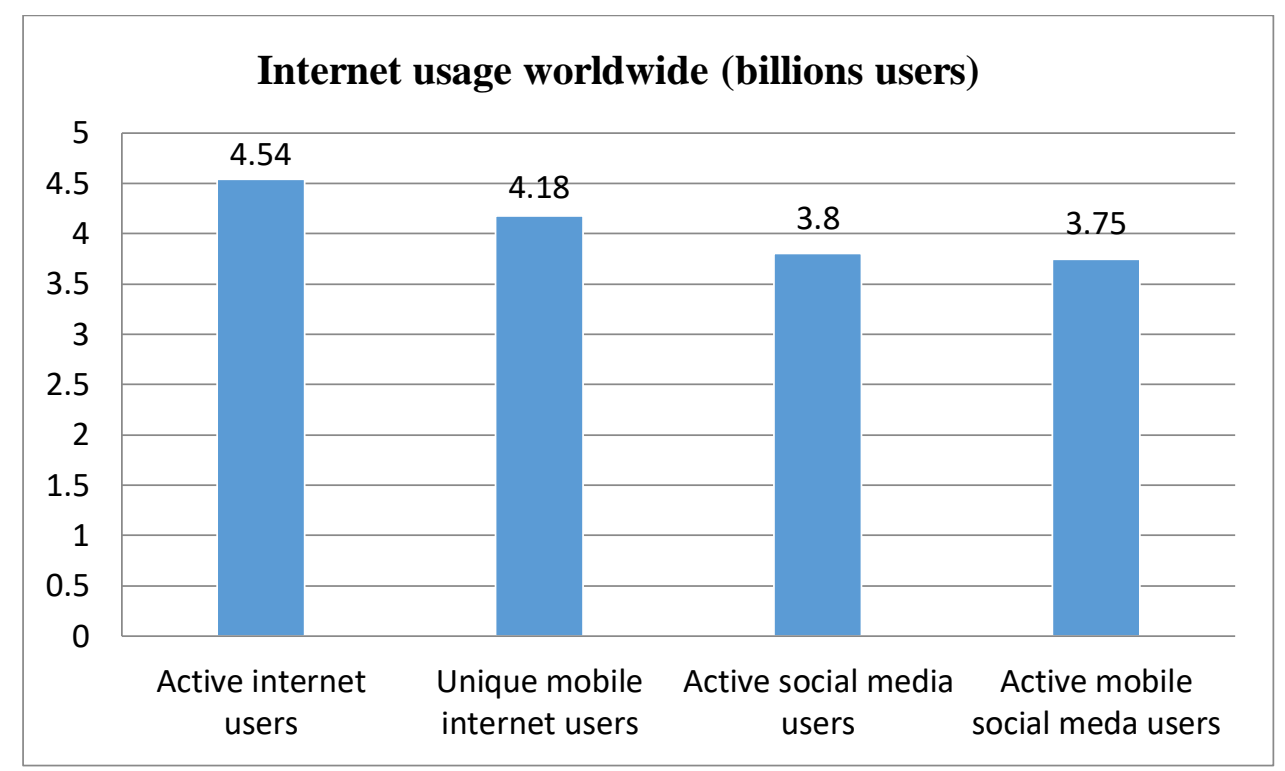

Fig. 2. Statistics regarding the internet usage around the world [13]

As in traditional e-commerce's case, there are some series of advantages and disadvantages related to the m-commerce. One of the advantages is represented by convenience, as $\mathrm{m}$-commerce users are not limited to any physical space required for a computer, any cables or even special internet connections, since the costs of $3 \mathrm{G}, 4 \mathrm{G}$ and in the future even $5 \mathrm{G}$ technologies are affordable in most of the countries around the globe. Also, mobile commerce applications and websites are designed to be time efficient, so the users do not have time to be distracted and abandon the placement of an order. Thus, through something as easy as four screen taps, given that you store the relevant data like personal details, billing and delivery address and card details in case you want to pay immediately, you can successfully place an order.

Among disadvantages related to $\mathrm{m}$ commerce, we notice the technology limitations of mobile devices, as older ones fail to keep up with the level of performance needed to run newer applications smoothly. Also, some devices have small screens and graphics issues, therefore user experience and user interfaces need to be constantly improved, which translates into higher research and implementation costs. 


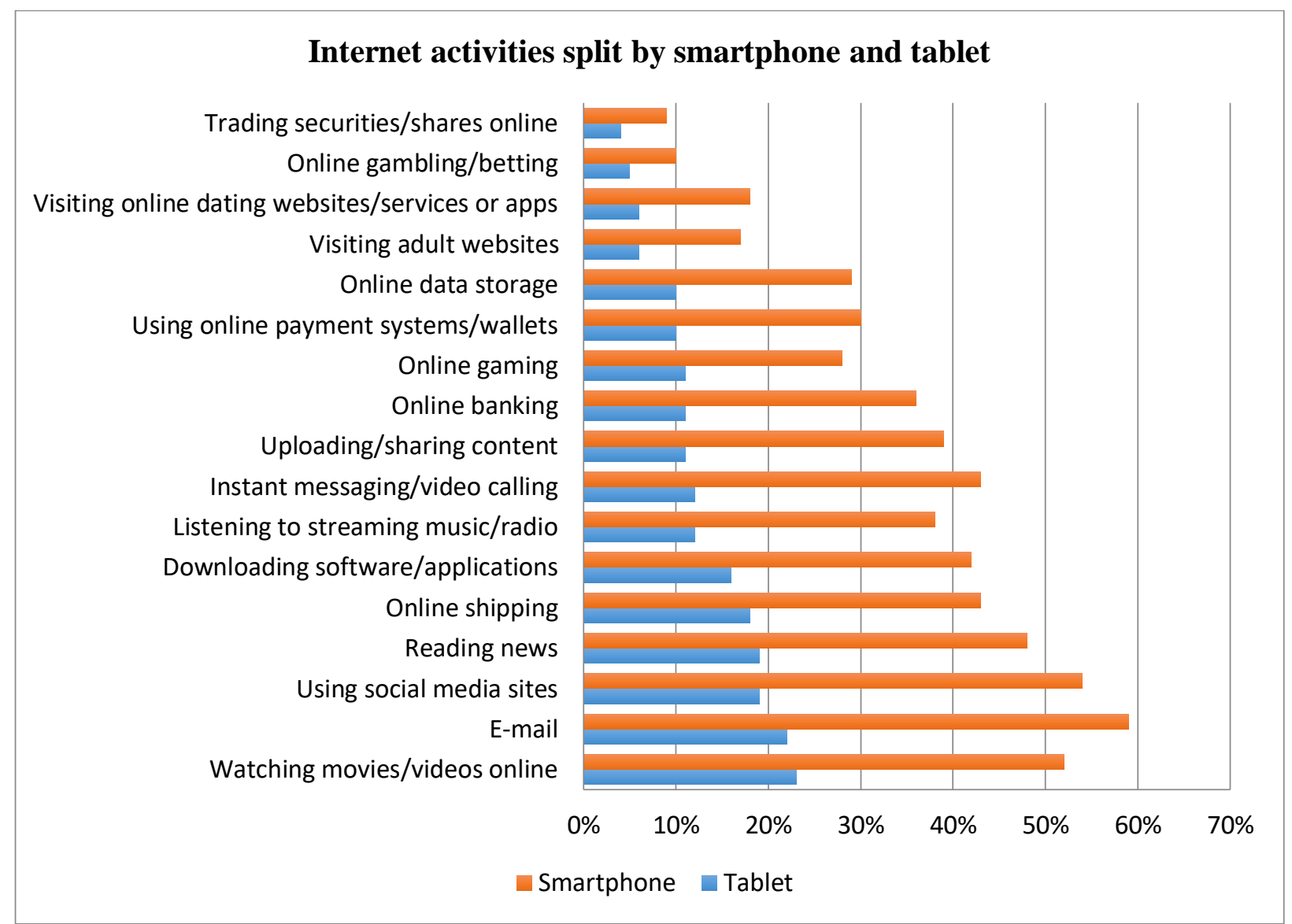

Fig. 3. Statistics regarding the most popular internet activities. Source: [14]

An online survey conducted in the second half of 2017 [14] reveals that while people spend their time using a smartphone, the main activities that they switch between are watching online videos and movies, from watching movies or TV series on various platforms to watching video content and taking part in courses taught on online platforms.

\section{Our Work}

Our main objective is to study the impact of m-commerce growth on the Gross Domestic Product (GDP). We analyzed data for two countries members of European Union: Germany, as a West European country with one of the most developed economies in the world and Romania, as an East European country with a fast-developing economy. We took into consideration various factors such as the number of internet users, the number of mobile internet users, as well as percentage of internet user out of the total population. Also, we studied the market evolution of e- commerce and m-commerce as well as the internet activities preferred by mobile users. The data was correlated with the GDP for the analyzed countries and the results were compared.

Hypothesis: The growth of e-commerce and m-commerce transactions has a positive impact on the GDP growth.

\section{Methodology}

Three categories of statistics were gathered. The first one is related to the internet access in these two analyzed countries and contains the evolution of internet adoption (mobile, broadband and dial-up), the number of households, the population and indices regarding this data. The second one is related to the GDP of the analyzed countries between 2014 and 2019 and the last one contains data about electronic commerce and mobile commerce during the same years. We used regression in order to correlate the data.

Table 1 shows the evolution of certain indices in Romania. Despite the fact that the 
population is slightly decreasing from one year to another, we can notice that the internet usage has a constant rate of growth. Even if Romania has excellent connectivity and high internet speed due to the fact that the infrastructure is new compared to other countries from European Union, there are still some dial-up connections left in the country. However, based on the current decrease rate among dial-up subscriptions, we estimate that until 2021, there will be no dial-up connections left in Romania.

Table 1. Statistics regarding internet usage in Romania. Source [15]

\begin{tabular}{|c|c|c|c|c|c|c|}
\hline Measure & 2014 & 2015 & 2016 & 2017 & 2018 & 2019 \\
\hline Population (millions) & 19.95 & 19.87 & 19.76 & 19.64 & 19.52 & 19.41 \\
\hline Households (millions) & 7.10 & 7.11 & 7.10 & 7.08 & 7.07 & 7.05 \\
\hline $\begin{array}{l}\text { Percentage of Population } \\
\text { Using The Internet }\end{array}$ & 54 & 56 & 60 & 64 & 71 & 74 \\
\hline Internet Users (millions) & 10.20 & 10.54 & 11.19 & 11.90 & 13.11 & 13.57 \\
\hline Broadband (millions) & 4.01 & 4.26 & 4.48 & 4.67 & 4.83 & 4.96 \\
\hline Dial-up & 49,000 & 37,000 & $\begin{array}{r}27,00 \\
0\end{array}$ & $\begin{array}{r}18,00 \\
0\end{array}$ & 10,000 & 3,000 \\
\hline $\begin{array}{l}\text { Mobile Internet Subscriptions } \\
\text { (millions) }\end{array}$ & 10.75 & 13.73 & 15.86 & 16.31 & 17.16 & 18.05 \\
\hline
\end{tabular}

In table 2, the statistics regarding internet usage in Germany show that the population is on a growth tendency and so does the internet usage. In contrast to Romania, since 2017, there are no dial-up internet connections left in Germany. During the analyzed period, the percentage of population using the internet in Germany went from $86 \%$ to $91 \%$, which is a growth of only 5 percentage points. Romania has presented a much more significant increase, starting from 54\% in 2014 and ending with $74 \%$ in 2019 . Despite the fact that Germany has a higher percentage of internet users overall, the growth rate was at a much higher pace in Romania.

Table 2. Statistics regarding internet usage in Germany. Source [15]

\begin{tabular}{|c|c|c|c|c|c|c|}
\hline Measure & 2014 & 2015 & 2016 & 2017 & 2018 & 2019 \\
\hline Population (millions) & 80.76 & 81.19 & 82.17 & 82.52 & 82.85 & 83.07 \\
\hline Households (millions) & 40.22 & 40.77 & 40.96 & 41.30 & 41.53 & 41.72 \\
\hline $\begin{array}{l}\text { Percentage of Population } \\
\text { Using The Internet }\end{array}$ & 86 & 88 & 88 & 89 & 90 & 91 \\
\hline Internet Users (millions) & 66.67 & 68.06 & 69.26 & 70.09 & 70.90 & 72.03 \\
\hline Broadband (millions) & 29.57 & 30.70 & 31.80 & 32.64 & 33.38 & 33.97 \\
\hline Dial-up & 897.00 & 464.00 & 97.00 & 0.00 & 0.00 & 0.00 \\
\hline $\begin{array}{l}\text { Mobile Internet Subscriptions } \\
\text { (millions) }\end{array}$ & 52.60 & 58.47 & 63.10 & 65.51 & 67.80 & 72.90 \\
\hline
\end{tabular}

Figures 5 and 6 illustrate the evolution of ecommerce and m-commerce in Romania and in Germany. When comparing the evolution of both traditional and mobile e-commerce in these two countries, we can observe that while in Germany the growth rate was relatively constant, in Romania, 2017 was a turning point where e-commerce started to grow at a faster rate. In the following years, we expect that e-commerce market will continue to grow, but at lower pace in Germany compared to Romania, since German users were early ecommerce adopters and the e-commerce German market is already relatively mature. On the other hand, a high yearly growth in the 
e-commerce market is still expected in

Romania for the next few years.

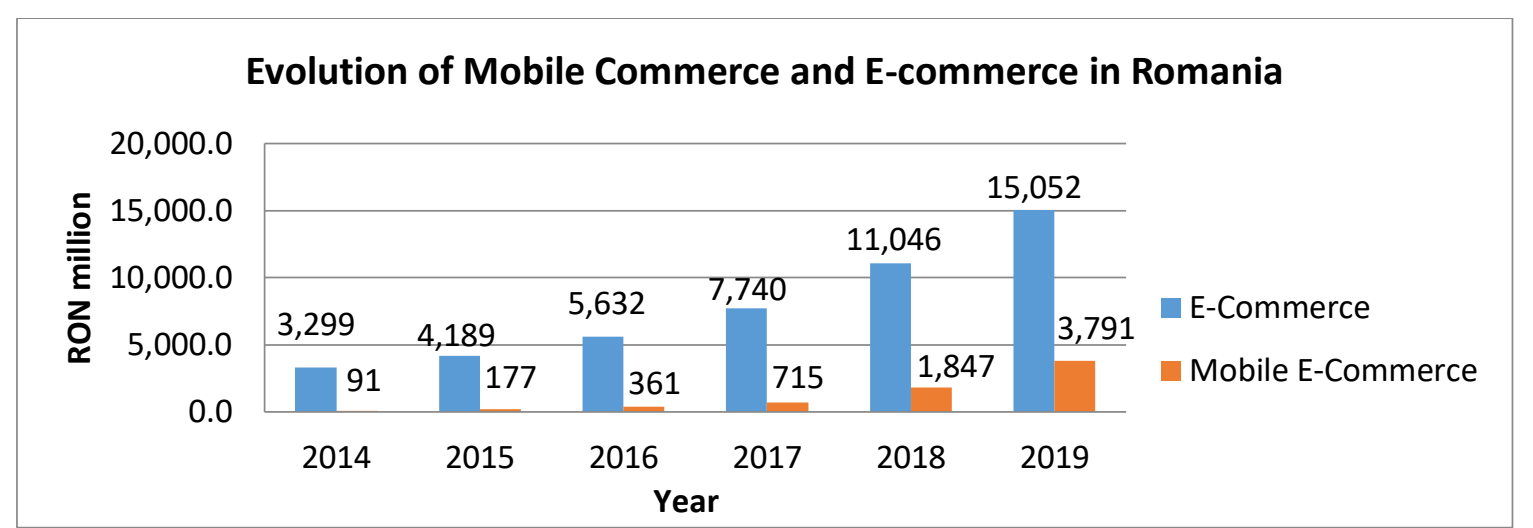

Fig. 4. Evolution of Mobile Commerce and Electronic Commerce in Romania. Sources: [16], [17]

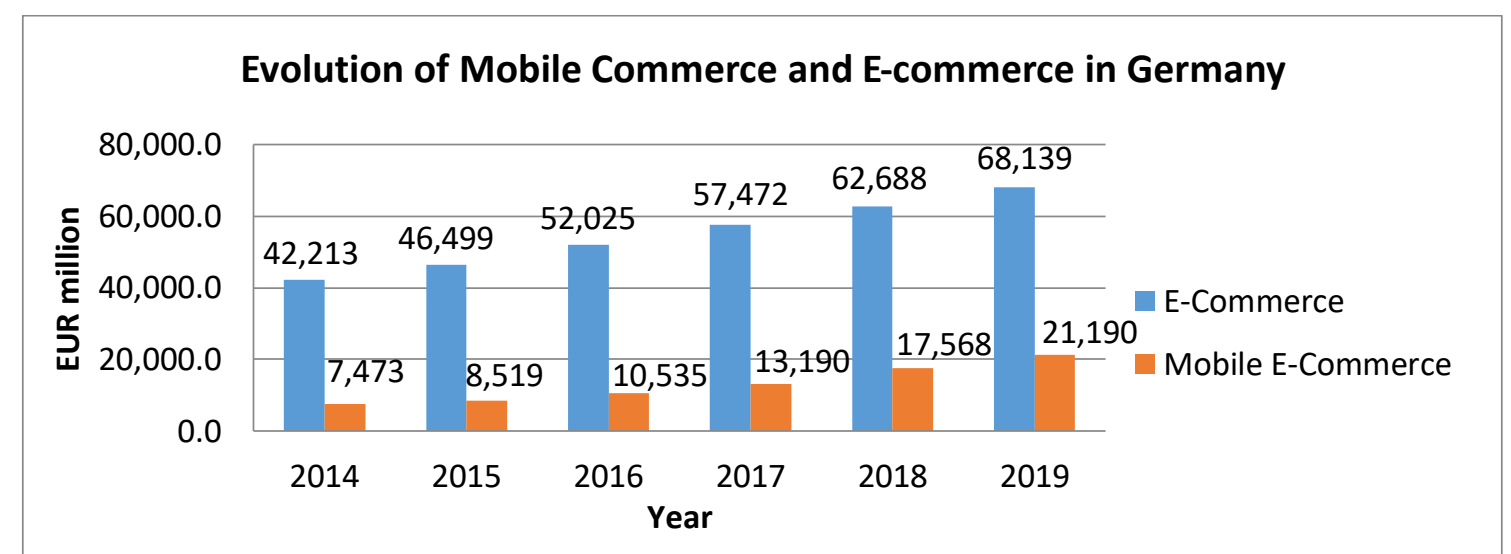

Fig. 5. Evolution of Mobile Commerce and Electronic Commerce in Germany. Sources: [18],

[19]

In both figure 6 and figure 7 we can see the commerce datasets were calculated based on evolution of the GDPs in both countries. For current prices. more precise results, both the GDP and e-

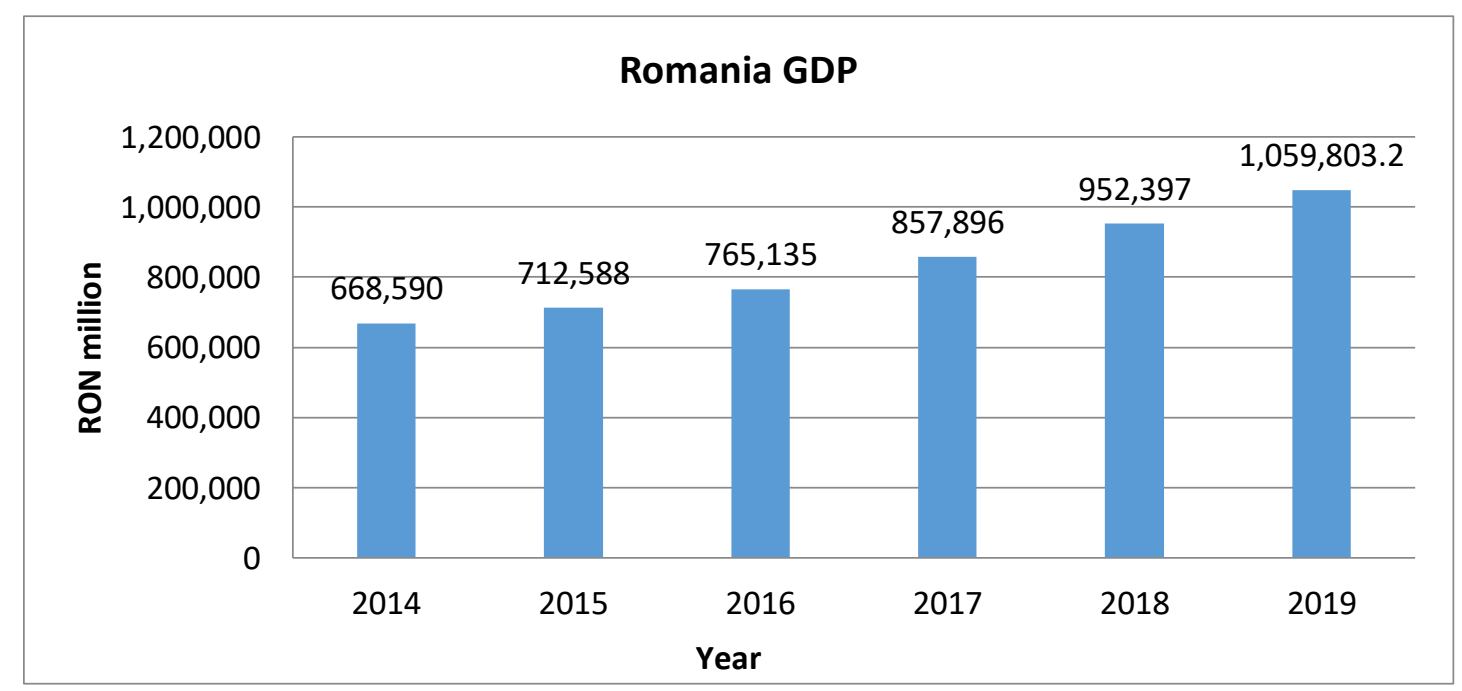

Fig. 6. Evolution of Romanian's GDP. Source [20] 


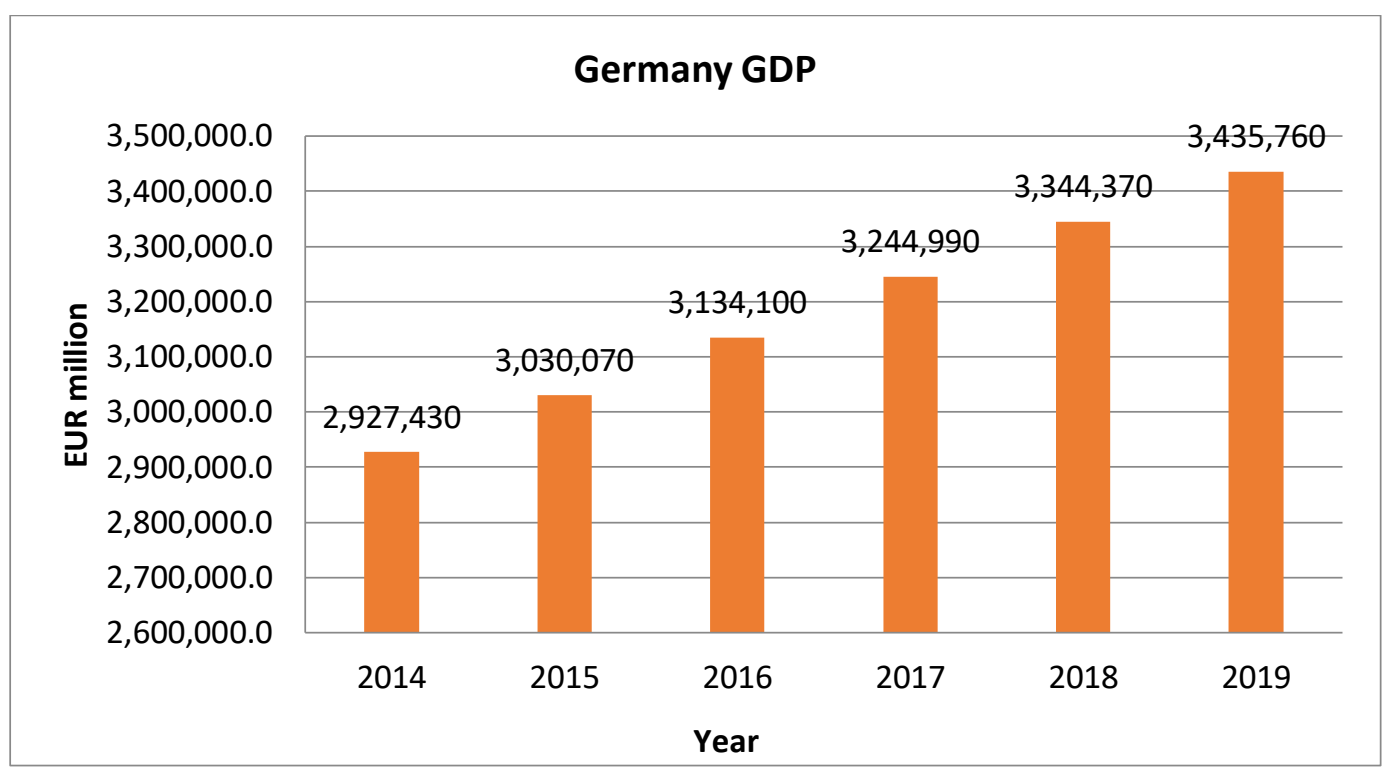

Fig. 7: Evolution of Germany's GDP. Source [20]

A correlation was made between the values of the mobile commerce reported to the GDP in each country in order to see to what extent the growth of mobile commerce influences the growth of the GDP. The correlation formula that was used in our study is:

$$
\text { (1) } \quad r=\frac{\sum(x-\underline{x})(y-\underline{y})}{\sqrt{\sum(x-\underline{x})^{2} \sum(y-\underline{y})^{2}}}
$$

where $\mathrm{x}$ - values of mobile commerce, $\mathrm{y}$ values of GDP and $r$ is the correlation coefficient which can take values within the interval -1 and 1 .

\section{Results}

In order to validate our hypothesis, we calculated the correlation coefficient $\mathrm{r}$ for Romania and Germany. Figure 8 shows both the mobile commerce values and GDP in the same chart. After running the correlation formula between the two datasets, we obtained a correlation coefficient of 0.9424 . Since the value of $r$ is very close to +1 , this indicates a very strong positive linear relation between the sales volumes in the mobile commerce and the GDP.
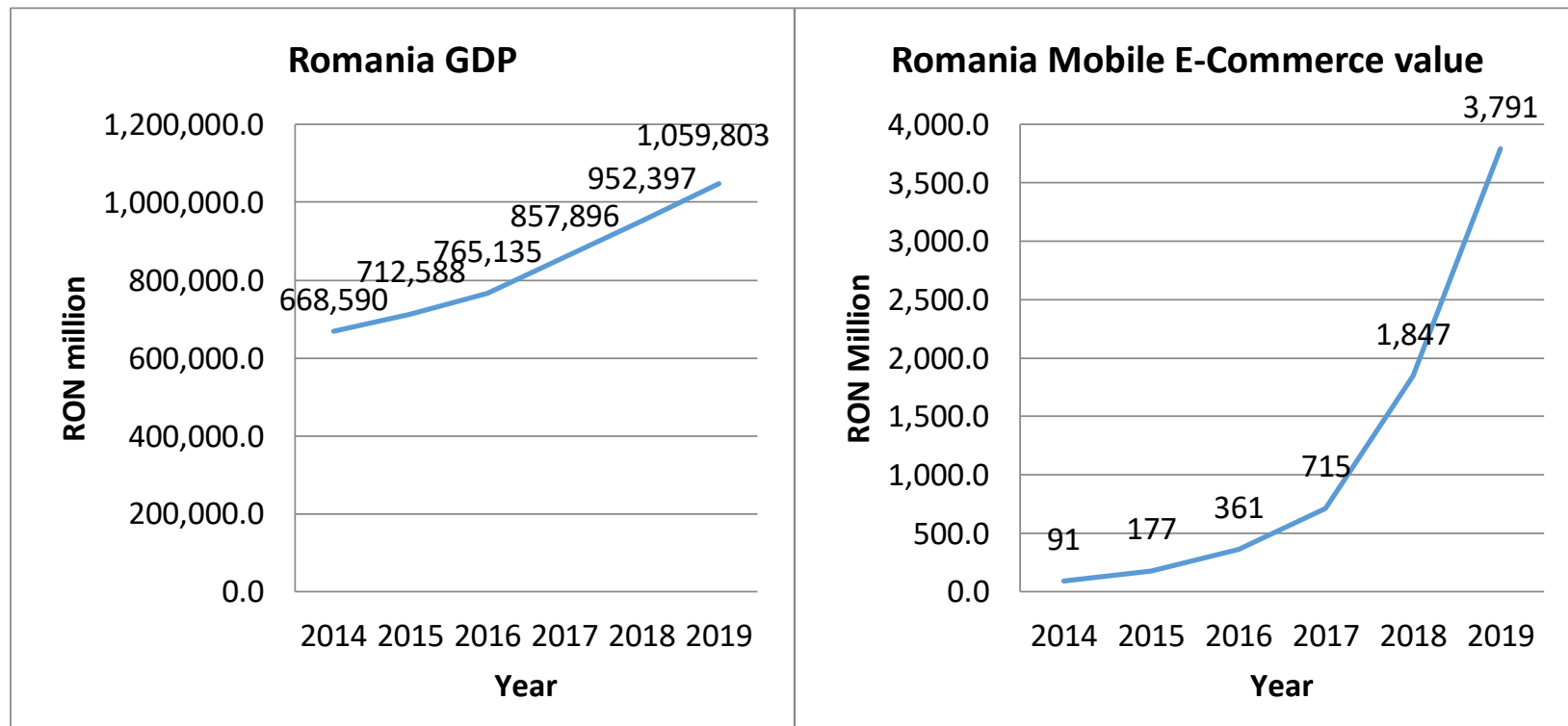

Fig. 8. Mobile commerce vs. GDP in Romania. Sources [17], [20] 
The GDP growth rate is high and relatively constant indicating a fast-developing economy. The m-commerce value growth rate for the analyzed time interval is remarkably high, exceeding $100 \%$ per year, on average. As expected, this increase in value has a positive impact on GDP.
Same analysis was conducted for the data about Germany (figure 9). In this case, the correlation coefficient was 0.9740 , which is even closer to +1 , that being translated into a stronger correlation between these two variables.

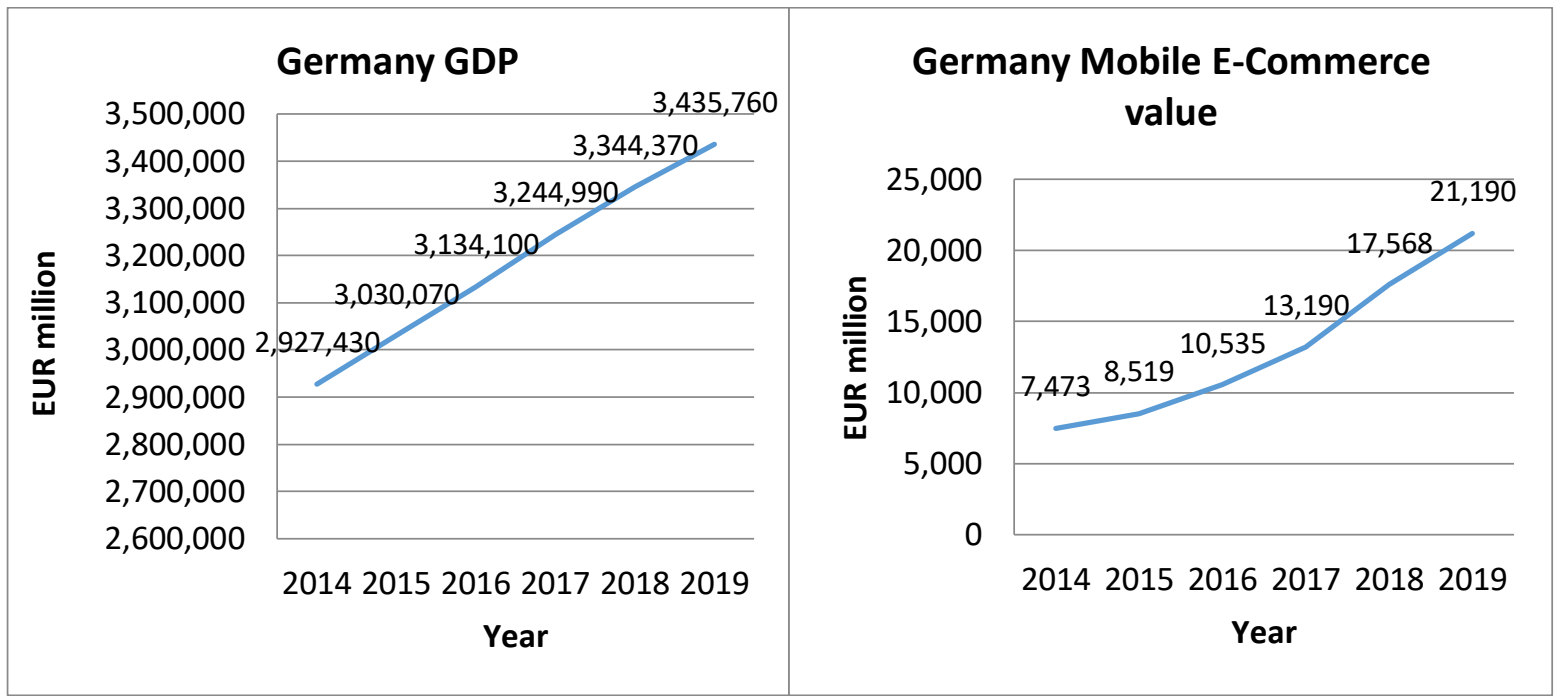

Fig. 9. Mobile commerce vs. GDP in Germany. Source [19], [20]

Germany has one of the most developed economies in the world. The constant growth rate for the analyzed interval indicates a sustainable economy. Regarding $\mathrm{m}$ commerce value, there is a relative constant yearly growth rate, with an average of $23.33 \%$.

The high values of the correlation coefficients obtained for both Romania and Germany validate our hypothesis. Although the economic situations as well as the growth rate of the two countries are different, the $r$ values are very close.

\section{The impact of Covid-19 pandemic state over the worldwide e-commerce trends}

Since the study presented in the previous section analyzes regarding $\mathrm{m}$-commerce, as a branch of e-commerce, in the context of a stable economy, we considered important to continue our work and study the main changes in the general consumer behavior towards ecommerce. We chose to analyze data for some of the earliest and the most affected countries by COVID-19 for two reasons: (1) the economic changes were felt earlier, also (2) the challenges for these countries are higher. However, although Germany is one of the countries who managed the pandemic situation very well (considering the low mortality rate of COVID-19 patients, we also included data about this country in order to compare the current situation with the previous one.

Another aspect considered when choosing which countries to study was based on the availability of data, since this article approaches up to date problems.

On Wednesday, March 10, the World Health Organization classified the rise of the new coronavirus as a global pandemic. Worldwide, economic sectors were affected by the need for social distancing measures and electronic commerce did not make an exception.

A recent study gathered data about how the Covid-19 pandemic influences the global retail market. While schools, bars, restaurants, and non-necessity stores were temporarily closed and any tourist activities banned, 
people switched to work from home where possible. This resulted in some of the economy sectors being blocked [21].

Fig. 10 shows how much consumer packaged goods (CPG) sales vary compared to the same period of 2019. Consumer packaged goods, or fast-moving consumer goods (FMGC) is a term used for those products that are replaced frequently, such as food, drinks, cosmetics and cleaning products.

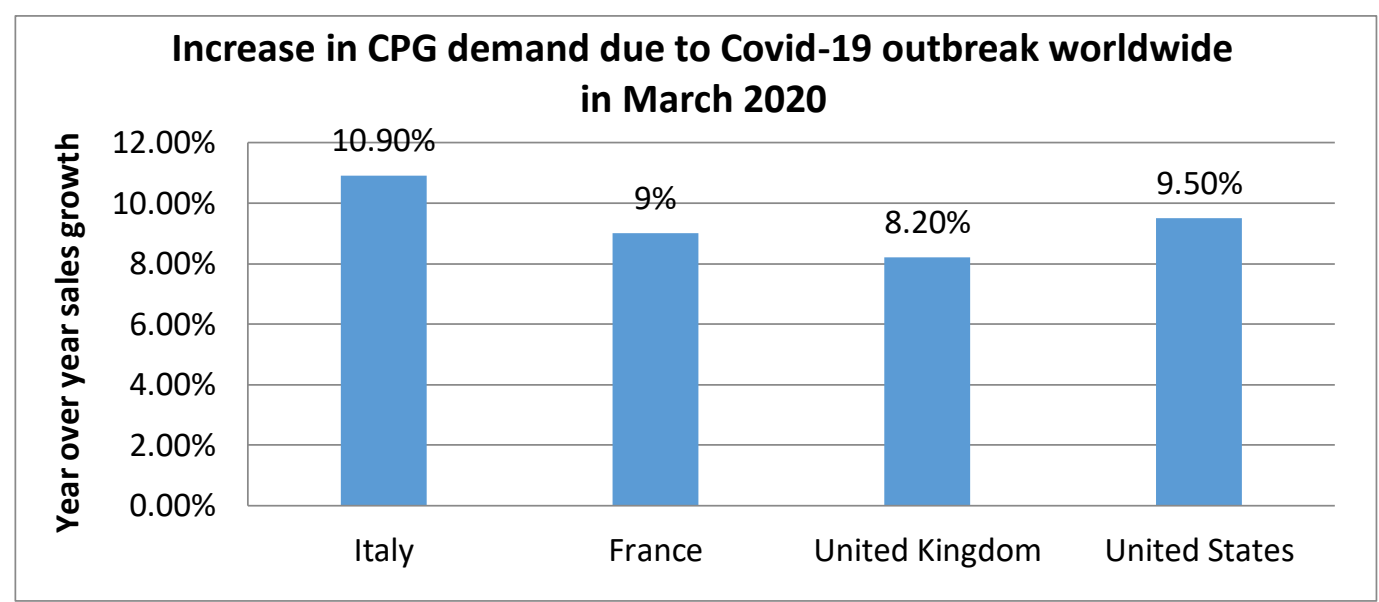

Fig. 10. The year over year growth of consumer packaged goods (CPG) sales due to Covid-19 (March 2020 over March 2019). Source [22]

While people switched to working from home and maintaining social distancing measures, their internet consumption behavior changed as well. Figure 11 shows, which market segments were positively impacted and which segments went down in sales. The analysis was made in April compared to January and February on 1400 websites. Supermarket and retail tech were the most positively impacted two segments and the third one is telecom. The increase in these three categories could be caused by the fact that most people switched to working from home where possible, hence the need for office specific devices. The most affected segment was tourism, as most of the hotels, airlines and agencies suspended their activities.

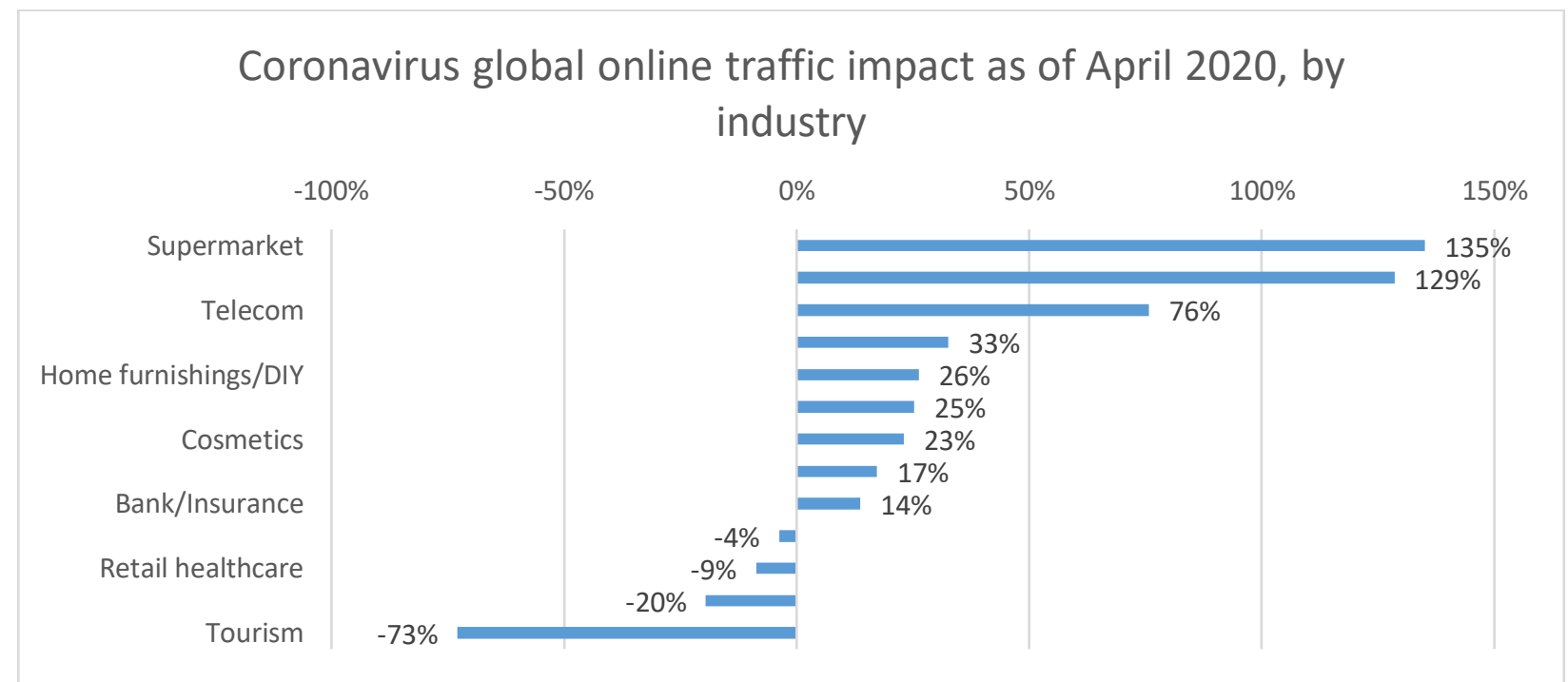

Fig. 11. The impact of Covid-19 on global internet traffic, by industry. Source [23]

Figure 12 illustrates the evolution of the retail segments in China, the global pandemic starting point. We can clearly see that for most of the categories presented there has been a 
decrease in sales, from $6.6 \%$ for products of are goods of prime necessity such as grain, oil daily usage, to $41.1 \%$ for precious metals. The only categories that were positively impacted and food, beverages and medicines, which had a very little increase in sales.

Nominal retail sales growth in China January-February 2020

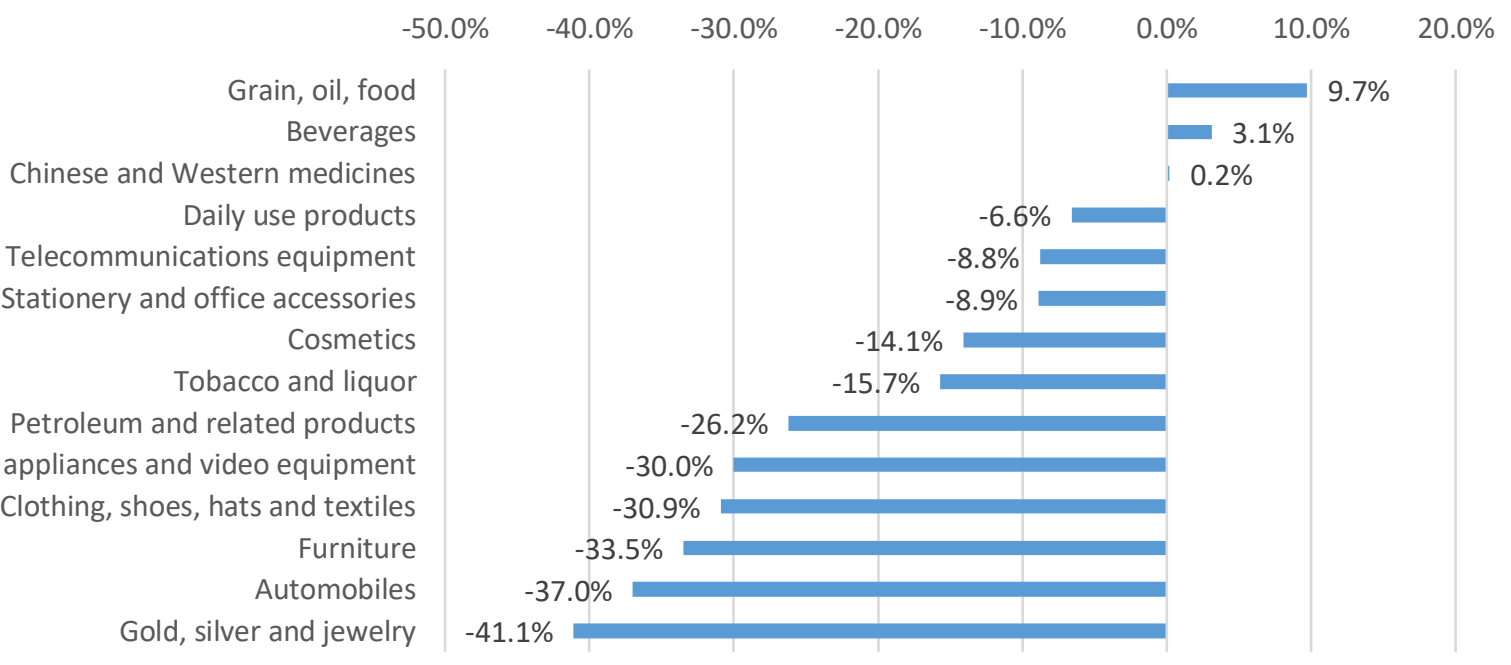

Fig. 12. Retail segments growth in China in January-February 2020. Source [24]

Table 3 shows the results of a survey face masks, washing hands more often, conducted by Statista at the end of April 2020 cleaning the house more and using less cash, on 2,861 respondents that analyses the general and social distancing measures such as staying behavior changes caused by Covid-19. We at home more, travelling less, shopping online can see that most of them changed their more than going to physical stores and lifestyle in accordance with both increased switching to working from home instead of personal hygiene such as wearing protective commuting to the office.

Table 3. Changes to the general lifestyle due to Covid-19 in selected countries 2020. Source [25]

\begin{tabular}{lccrr} 
& China & Germany & $\begin{array}{r}\text { United } \\
\text { Kingdom }\end{array}$ & $\begin{array}{l}\text { United States } \\
\text { Wear protective face masks }\end{array}$ \\
\hline Washed hands more & $78 \%$ & $49 \%$ & $14 \%$ & $65 \%$ \\
\hline Stayed at home more & $74 \%$ & $74 \%$ & $77 \%$ & $77 \%$ \\
\hline Applied social distancing & $69 \%$ & $75 \%$ & $85 \%$ & $81 \%$ \\
\hline Avoided public transport & $61 \%$ & $62 \%$ & $80 \%$ & $79 \%$ \\
\hline Travelled less & $61 \%$ & $53 \%$ & $66 \%$ & $39 \%$ \\
\hline Shopped online more & $61 \%$ & $52 \%$ & $74 \%$ & $60 \%$ \\
\hline Gone to the shops less & $61 \%$ & $30 \%$ & $40 \%$ & $56 \%$ \\
\hline Avoided public places & $60 \%$ & $65 \%$ & $76 \%$ & $67 \%$ \\
\hline Cancelled plans with family or friends & $59 \%$ & $62 \%$ & $67 \%$ & $67 \%$ \\
\hline Used less cash & $50 \%$ & $61 \%$ & $64 \%$ & $56 \%$ \\
\hline Cleaned the house more & $50 \%$ & $36 \%$ & $63 \%$ & $38 \%$ \\
\hline
\end{tabular}




\begin{tabular}{lllll} 
Worked from home & $41 \%$ & $26 \%$ & $32 \%$ & $29 \%$ \\
\hline Avoided certain shopping times & $32 \%$ & $36 \%$ & $41 \%$ & $40 \%$ \\
\hline Reduced exercises regime & $27 \%$ & $17 \%$ & $22 \%$ & $18 \%$ \\
\hline
\end{tabular}

Another survey [26] conducted in March 2020 on 9,931 respondents shows that most of them reduced the activity of going to physical stores for day-to-day consumer goods. As seen in figure 13, almost $79 \%$ of the respondents from Italy, which was severely affected by the Covid-19 pandemic, answered positively.

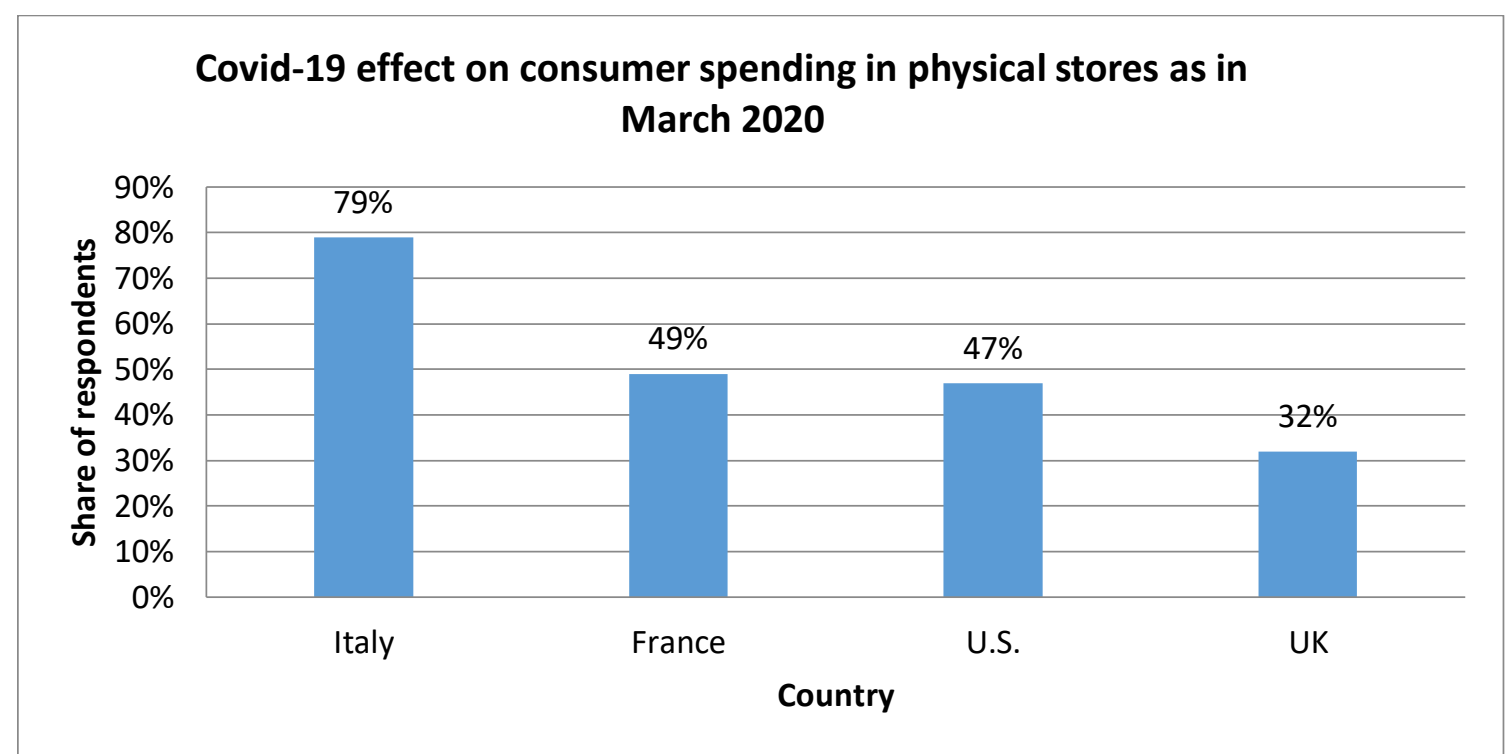

Fig. 13. Effect of Covid-19 on consumer spending in physical stores worldwide in March 2020. Source [26]

Figure 14 illustrates the results of a survey [27] conducted on 10,000 respondents worldwide analyzed the e-commerce purchasing frequency variation due to the pandemic state. We can observe the differences between customers' behaviors for 12 of the most effected countries by the pandemic in the world.

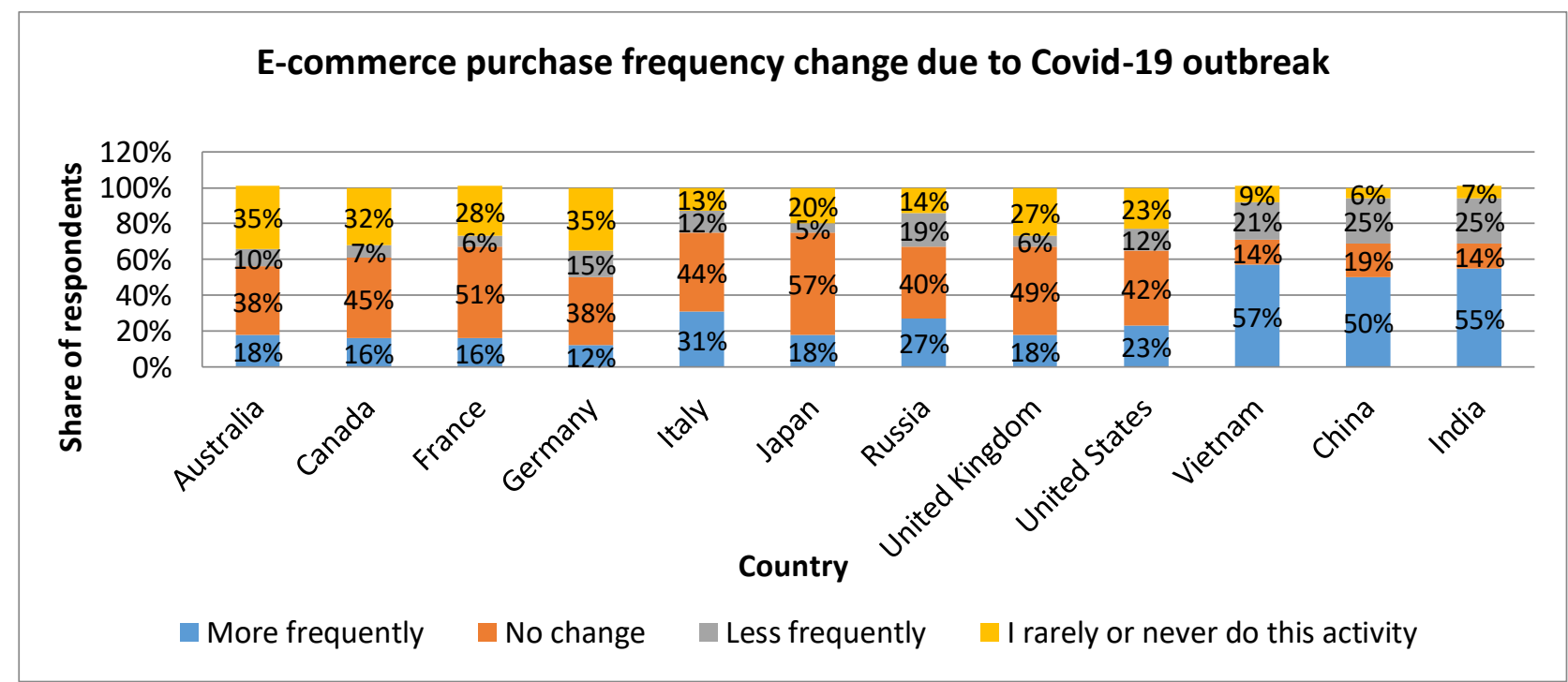

Fig. 14. E-commerce purchase frequency change due to Covid-19 in 2020. Source [27] 


\section{Results}

All the industries suffered severe changes due to the COVID-19 pandemic. Although the global economy is in decline, some sectors show an increase in values, e-commerce being one of them.

Due to isolation measures and recommendations the consumer spending in physical stores decreased severely. Thus, people switched from buying from physical stores to e-commerce. As seen in fig. 17, more than half of respondents in Vietnam, China and India declared that they do purchase online more frequently than before, followed by Italy with one third of respondents.

On the other hand, in half of the analyzed countries, less than $20 \%$ of the respondents declared that they increased their online shopping activities (12\% in Germany, $16 \%$ in France and Canada, $18 \%$ in Australia, Japan and the United Kingdom). However, in all the above-mentioned countries, a high percentage of respondents reported no change in the purchase frequency. This can be attributed to the high level of e-commerce already existing in all these countries before COVID-19 started.

Also, although the global internet traffic spent for e-commerce in general increased tremendously, there are some industries where it decreased, such as jewelry, retail healthcare, luxury products and tourism.

The general behavior of e-commerce consumers was severely changed during March and April 2020. It is expected that these shifts will last on some degree even when the COVID-19 pandemic will stop, therefore the e-commerce sector will continue to grow. We assume that the longer the pandemic will last, the more people will migrate from physical stores to online shopping.

\section{Conclusions and future work}

During our research, we analyzed a series of papers related to both electronic and mobile commerce in order to see if there is any significant influence of mobile commerce growth on the Gross Domestic Product of a country.
Furthermore, we gathered several datasets regarding mobile and electronic commerce activity over a certain period of time in these two countries and analyzed them in terms of correlation in order to demonstrate that the growth of m-commerce and e-commerce is directly related to the growth of GDP both in Romania and Germany.

Both electronic commerce and mobile commerce have known a continuous increase in market share during the past years and as the trends suggest, there is plenty of space to grow for both of them, which will lead to the development of specific adjacent industries, such as software engineering, user interface \& user experience design, databases, security, marketing and specific advertising.

As demonstrated above, the growth of both ecommerce and m-commerce does have a positive impact on the Gross Domestic Product in the analyzed countries. Furthermore, the Covid-19 pandemic state which was declared globally influenced in a positive manner the electronic commerce shopping worldwide, but the impact on GDP is not conclusive as there were other industries which were affected by this state.

As future work, we will continue to study the impact of electronic commerce growth on the GDP on other countries as new data becomes available. Moreover, we will continue to monitor data related to Covid-19 pandemic and see how electronic commerce will be impacted on a longer term, as relaxation measures start to be implemented worldwide.

\section{References}

[1] Chaffey and Fiona Ellis-Chadwick, Digital marketing, Pearson UK, 2019.

[2] Simon Kingsnorth, Digital marketing strategy: an integrated approach to online marketing, Kogan Page Publishers, 2019.

[3] Petrock, Victoria. US Virtual and Augmented Reality Users (2020). eMarketer. [Online] 2020. https://www.emarketer.com/content/usvirtual-and-augmented-reality-users2020

[4] K. W. Su, S.C. Chen, P.H. Lin, and C. I. Hsieh, Evaluating the user interface and 
experience of $V R$ in the electronic commerce environment: a hybrid approach, vol. 24, Springer, 2019.

[5] Chang Lulu, See how that couch would look in your living room in AR with Ikea Place, Digital Trends [Online], 2018, https://www.digitaltrends.com/home/ikea -place-ar/.

[6] Rayome, Alison DeNisco. How Sephora is leveraging AR and AI to transform retail and help customers buy cosmetics. Tech Republic. [Online] 2018. https://www.techrepublic.com/article/ho w-sephora-is-leveraging-ar-and-ai-totransform-retail-and-help-customers-buycosmetics/.

[7] Dushyant Kaushik, Gupta Ankur, and Gupta Swati, E-Commerce Security Challenges: A Review, 2020, SSRN, 2020. 3595304.

[8] Shazia W. Khan, Cyber security issues and challenges in E-commerce, SSRN, 2019. 3323741.

[9] Safa Kaabi and Rim Jallouli., Overview of E-commerce Technologies, Data Analysis Capabilities and Marketing Knowledge, International Conference on Digital Economy, Springer, Cham, 2019.

[10] Constantine Katsikeas, Leonidas Leonidou, and Athina Zeriti, Revisiting international marketing strategy in a digital era, vol. International Marketing Review, Emerald Publishing Limited, 2019

[11] Konstantinos Fouskas, Olga PachniTsitiridou, and Chrysa Chatziharisto, $A$ Systematic Literature Review on ECommerce Success Factors, vol. Strategic Innovative Marketing and Tourism, Cham : Springer, 2020

[12] Niranjanamurthy, M. et al, Analysis of e-commerce and m-commerce: advantages, limitations and security issues. International Journal of Advanced Research in Computer and Communication Engineering, pg. 23602370, vol. 2, no. 6, 2013

[13] Statista. Worldwide digital population as of April 2020. Statista. [Online] 2020. https://www.statista.com/statistics/61713 6/digital-population-worldwide/.

[14] Statista. Most popular mobile internet activities according to internet users worldwide as of 2nd half 2017, by device. Statista. [Online] 2019. https://www.statista.com/statistics/24976 $1 /$ most-popular-activities-carried-out-onmobile-internet-devices/.

[15] Euromonitor. Economies and Consumers Annual Data. Euromonitor International. [Online] 2020. https://www.euromonitor.com/.

[16] Euromonitor. E-Commerce in Romania. Euromonitor International. [Online] 2020. www.euromonitor.com/ecommerce-in-romania/report.

[17] Euromonitor. Mobile E-Commerce in Romania. Euromonitor International. [Online] 2020. www.euromonitor.com/mobile-ecommerce-in-romania/report.

[18] Euromonitor. E-Commerce in Germany. Euromonitor International. [Online] 2020. www.euromonitor.com/ecommerce-in-germany/report.

[19] Euromonitor. Mobile E-Commerce in Germany. Euromonitor International. [Online] 2020. www.euromonitor.com/mobile-ecommerce-in-germany/report.

[20] Euromonitor. Economies and Consumers Annual Data. Euromonitor International. [Online] 2020. https://www.euromonitor.com/.

[21] Statista. Coronavirus: impact on the retail industry worldwide. Statista. [Online] 2020. https://www.statista.com/study/71767/cor onavirus-impact-on-the-global-retailindustry/.

[22] Statista. Increases in CPG demand due to COVID-19 outbreak worldwide March 2020, by country. Statista. [Online] 2020.

https://www.statista.com/statistics/11054 09/coronavirus-change-in-cpg-purchasesby-country-worldwide/.

[23] Statista. Coronavirus impact on online traffic of selected industries worldwide in 
week ending April 26, 2020. Statista. [Online] 2020. https://www.statista.com/statistics/11054 86/coronavirus-traffic-impact-industry/.

[24] Statista. Nominal retail sales growth in China January-February 2020, by product category. Statista. [Online] 2020. https://www.statista.com/statistics/11076 08/china-yoy-nominal-retail-salesgrowth-during-coronavirus-covid19outbreak-by-product/.

[25] Statista. Thinking about your everyday life, since the COVID-19 / coronavirus pandemic, have you made any changes to your general lifestyle?. Statista. [Online] 2020.

https://www.statista.com/statistics/11059 60/changes-to-the-general-lifestyle-dueto-covid-19-in-selected-countries/.

[26] Statista. Have you already reduced your spend on day-to-day in-store purchases due to the coronavirus?. Statista. [Online] 2020. https://www.statista.com/statistics/11060 00/coronavirus-in-store-spendingbehavior-of-consumers-worldwide/.

[27] Statista. Change in e-commerce usage to purchase products normally bought instore due to coronavirus (COVID-19) worldwide as of March 15, 2020, by country*. Statista. [Online] 2020. https://www.statista.com/statistics/11055 97/coronavirus-e-commerce-usagefrequency-change-by-countryworldwide/.

[28] Statista. Most popular mobile internet activities according to internet users worldwide as of 2 nd half 2017, by device. Statista. [Online] 2019. https://www.statista.com/statistics/24976 $1 /$ most-popular-activities-carried-out-onmobile-internet-devices/.

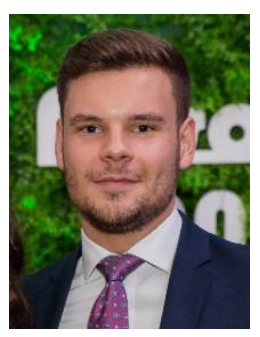

Florin-Valeriu PANTELIMON graduated the Faculty of Cybernetics, Statistics and Economic Informatics in 2015. He is currently a student at the Informatics Systems for the Management of Economic Resources Master program at the Bucharest University of Economic Studies. He has been working as a software developer for several companies ranging from consulting companies, healthcare and clinical trials to international stock exchanges and game development companies. His main fields of interest are entrepreneurship, cloud computing and web development.

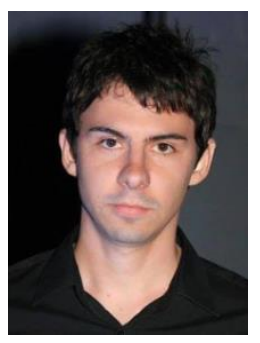

Tiberiu-Marian GEORGESCU graduated the Faculty of Cybernetics, Statistics and Economic Informatics in 2012. In 2015 he graduated the Informatics Systems for the Management of Economic Resources Master program. He completed his $\mathrm{PhD}$ program in Economic Informatics in September 2019 at the Bucharest University of Economic Studies. Currently, he is working as a Research Assistant in the Department of Economic Informatics and Cybernetics at the Bucharest University of Economic Studies. His main fields of interest are cybersecurity, machine learning and natural language processing.

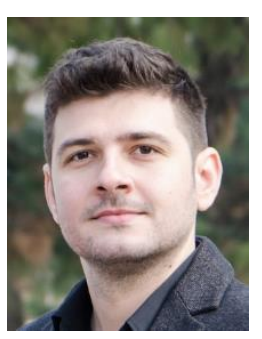

Bogdan-Ştefan POSEDARU graduated from the Faculty of Business and Tourism in 2012. He is currently a student at the Informatics Systems for the Management of Economic Resources Master program at the Bucharest University of Economic Studies. He worked as a freelancer in the IT field for 3 years. He was a member in various research projects, and since September 2018 he is one of the three co-founders of the start-up Chess Coders (https://chesscoders.com/). His main fields of interest are web technologies and natural language processing. 